\title{
Generation Structure, Prices, and Tariffs in the Russian Electric Power Industry in 2009-2018
}

\author{
M. Yu. Vasilyev*
}

Melentiev Energy Systems Institute of Siberian Branch of Russian Academy of Sciences, Irkutsk, Russia

\begin{abstract}
The paper aims to summarize and analyze the statistical data on the generation structure and price behavior in the Russian electric power industry and, based on the analysis, make a statistical contribution to the discussion on the outcomes of the electricity reform in Russia. A brief review of this topic is provided. The study states that the electric power industry should be regarded as a combination of four sub-industries when regulation, market design, and industrial organization problems are discussed. These four sub-industries are generation, transmission, distribution, and sales because of different regulations applied to these businesses. The main trends in the retail price index and some other indexes in the four sub-industries are observed from 2009 to 2018. The trends in electricity consumption and generation structure are discussed as essential components of economic processes in the industry. The findings suggest that the four sub-industries make different contributions to the overall growth of the electricity supply costs for end consumers. Most growth was determined by regulated governmentgranted monopolies in network businesses (transmission and distribution companies). The sales business is represented in the research by suppliers of last resort.
\end{abstract}

Index Terms: electricity market, industrial organization, electric power industry reform, deregulation.

\footnotetext{
${ }^{*}$ Corresponding author.

E-mail: mikhail-vasilyev@yandex.ru
}

http://dx.doi.org/10.38028/esr.2021.02.0002

Received June 27, 2021. Revised July 05, 2021.

Accepted July 15, 2021. Available online July 23, 2021.

This is an open access article under a Creative Commons Attribution-NonCommercial 4.0 International License.

C) 2021 ESI SB RAS and authors. All rights reserved.

\section{INTRODUCTION}

Nearly two decades have passed since the electric power industry reform in Russia started. However, until now, the process has not finished. The market models and rules, legal arrangements change regularly. Discussion about whether the reform is a success, what shortcomings of the new structure are, and how to improve the market, continues.

The changes in statutory regulation of the electric power industry in some countries (the process is referred to as «liberalization» or «deregulation») resulted in lower prices for the end consumers and higher competition in electricity production and sales. In 2000-2010, the electricity price index (EPI) in Russia was significantly higher than the retail price index (RPI). Later it was comparable or slightly higher than RPI. Thus, despite the long-term industry reform, there was no price decrease, which draws criticism of the reform (for example, [1]-[3]). Some authors note some positive results of the reform, including, in particular, a decline in the failure rate and an increase in the fuel utilization efficiency at thermal power plants. The reform led to significant investments in generation (primarily due to the mechanism of capacity supply agreement) and in electric networks [4]. Some researchers confirm that the electricity price growth sustainably exceeded the inflation rate [5]-[6]. This opinion, however, is not shared by all. Some authors believe that the electricity price growth in 2010-2017 was lower than the inflation rate [7].

In general, the researchers conclude that the Russian electricity reform was not successful, and further regulatory changes are necessary. The discussion on the industry problems, their possible solutions, and research methods continues ([8]-[14]).

Research and discussions of the electricity market can encounter the following issues. Some authors consider the electric power industry to be an integral whole and make conclusions based on the statistical 


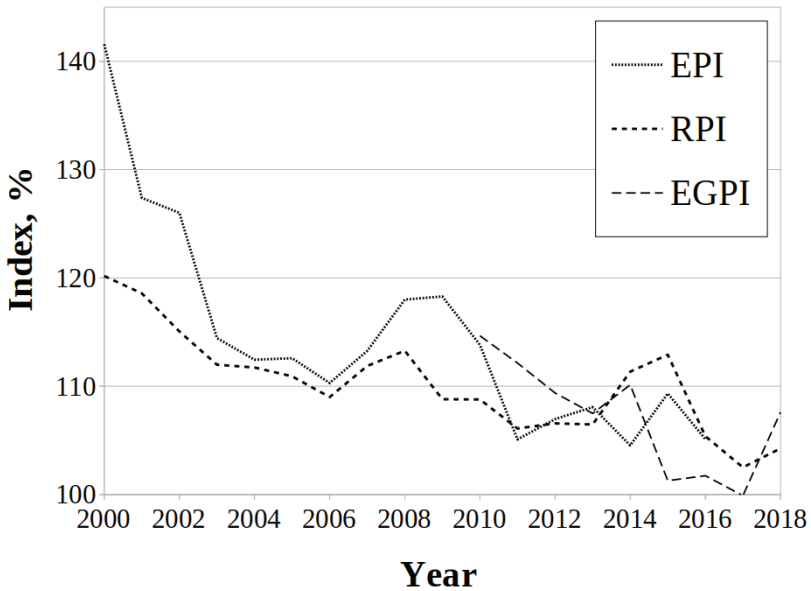

Fig. 1. Retail price index (RPI), electricity price index (EPI), and electricity generation price index (EGPI) in 2000-2018. Source: Federal State Statistics Service of the Russian Federation.

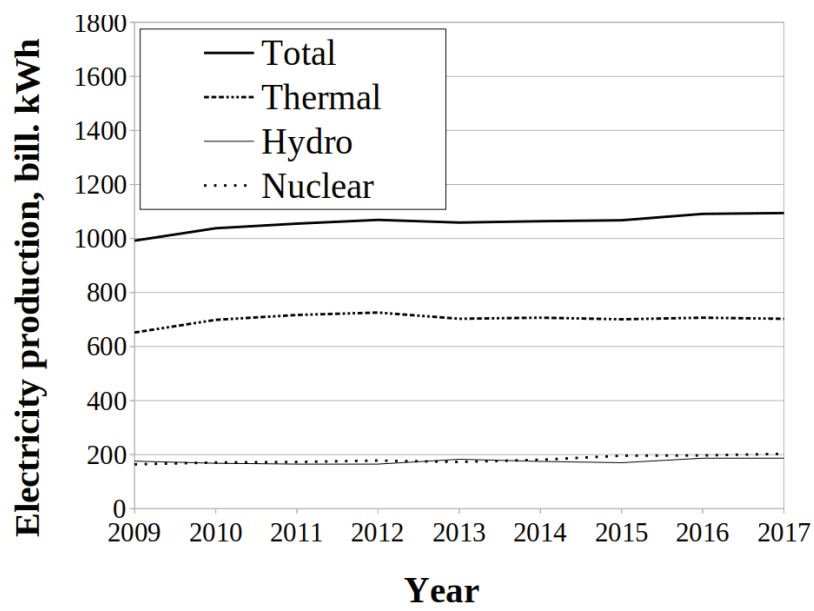

Fig. 3. Electricity production in 2009-2018 (bln. kWh per year). Source: Federal State Statistics Service of the Russian Federation.

and econometric data of the entire industry. In this case, conclusions can hardly be applied to the organization and regulation issues since the electric power industry is a complex entity. Part of it (electricity generation and sales) functions under competition conditions, and the other part (electricity transmission and distribution) is, in general, a government-granted monopoly. Generalized statistical data summarize the contribution of the industry parts but do not allow detecting the regulatory mechanisms, which create problems or provoke destructive by-effects. To provide an efficient policy, the electric power industry should be viewed as a combination of interdependent components, i.e., sub-industries (generation, transmission, distribution, and sales). The analysis should be based on statistical data that describe each of the industries separately. In particular, monopolistic power in the generation is analyzed in [15].

This research focuses on the years 2009-2018. A similar analysis of the previous decade can be found in [16].

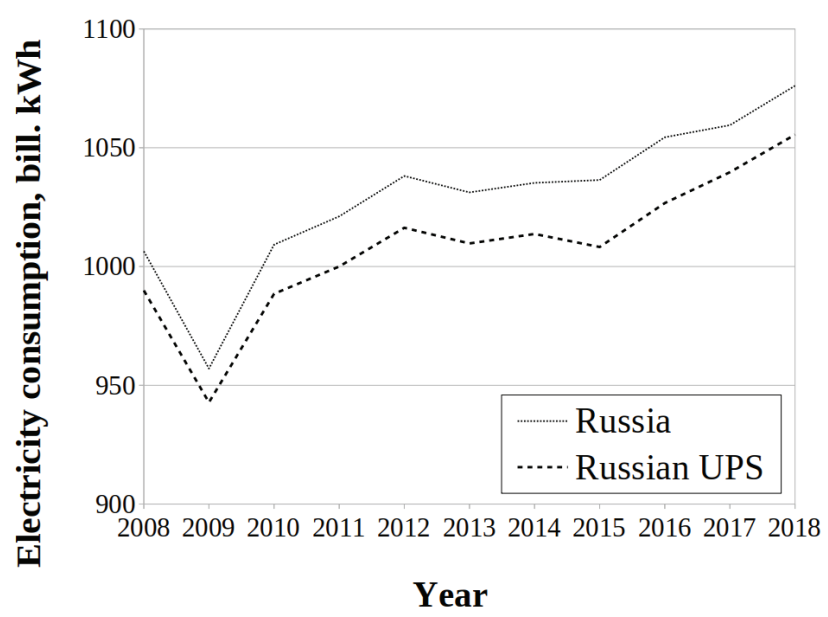

Fig. 2. Electricity consumption in the Russian Federation, including the consumption in the unified power system (UPS). Source - The System Operator of the Russian Federation.

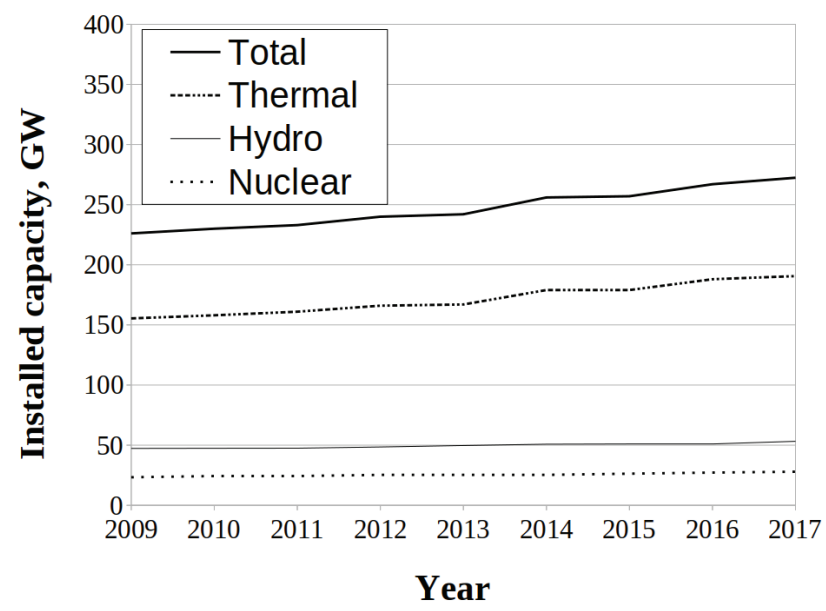

Fig. 4. Installed capacity of thermal, hydro, and nuclear power plants. Source: Federal State Statistics Service of the Russian Federation.

\section{INFLATION INDEXES AND ELECTRICITY CONSUMPTION}

Before analyzing the electric power sub-industries, let us introduce the benchmarking data that characterize the economic conditions in general, i.e., inflation and total electricity consumption. Fig. 1 presents the retail price index (RPI), electricity price index (EPI), and electricity generation price index (EGPI). Further analysis will use RPI as the benchmark of the price growth. RPI will be reduced to the price value in the earliest year under consideration and will show how the price would change if it changed proportionally to RPI (shown by dotted lines in the diagrams).

The diagram shows that EPI was constantly higher than RPI in 2000-2010, i.e., for the end consumers, the electricity price increased more quickly than the price of other commodities and services. Since 2011, EPI has been similar or slightly lower than RPI.

The electricity consumption in 2008-2018 is shown in Fig. 2. The difference between the two lines reflects the electricity consumption outside of the Russian unified 


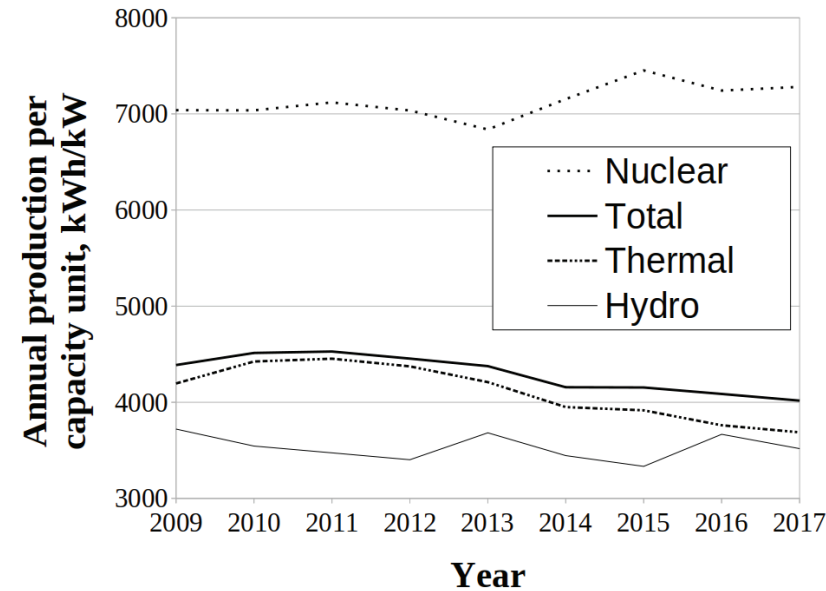

Fig. 5. Production performance of $1 \mathrm{~kW}$ of installed capacity of thermal, hydro, and nuclear power plants. Source: Federal State Statistics Service of the Russian Federation, calculations by the author.

power system. The total electricity consumption decrease in 2009 was followed by an intensive demand recovery in 2010, and, later, in 2011-2012, the growth was about $1.4 \%$ per year. After a stagnation of 2013-2014, the demand continued to rise with an average value of $1.5 \%$ per year, which implies that the economic situation of the considered period is characterized by rather stable growth of the total electricity consumption and by lower inflation than in the previous decade. This should be kept in mind in the analysis of electricity supply costs and tariffs.

The main components of the total electricity supply costs for the end consumers are the payments to the generators (for electricity and electric capacity) and the payments to the transmission and distribution networks. A noticeable part is a retail markup. The share of other payments, including those to the trading system administrator, system operator, and others, is less than $1 \%$ totally and is not considered in this paper.

\section{ELECTRICITY GENERATION}

Understanding the price changes requires the consideration of trends in generation. These trends are partly influenced by economic conditions, for example, through investments into profitable projects. And vice versa, the trends in generation structure determine prices. Thus, price changes should not be considered separately from the generation structure.

The electricity generation in Russia increased in 20002008 by $2 \%$ annually on average. In 2009 it decreased by $4.6 \%$. After recovery in 2010, the average annual growth was about $0.9 \%$ in $2011-2018$ (Fig. 3). The generated volumes changed differently for various power plants. Thus, the nuclear plants increased production by $2.6 \%$ annually in 2000-2017.

Within the same period, 2000-2017, hydropower plant generation changed depending on weather conditions and grew on average by $0.4 \%$ annually. The output of thermal

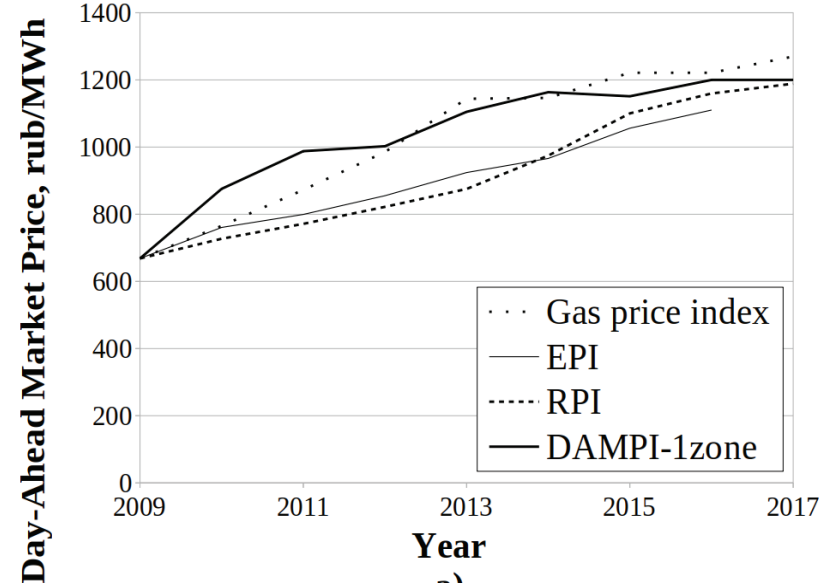

a)

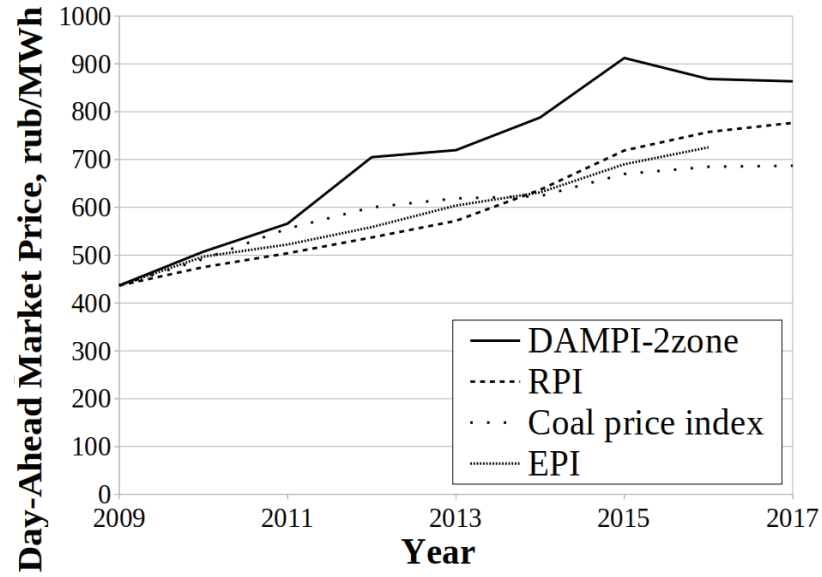

b)

Fig. 6. The day-ahead market prices in price zones I (a) and II (b) of the wholesale electricity market compared with the RPI, gas, and coal price indexes (reduced to the electricity price in 2009).

power plants increased in $2000-2008$ by $2.5 \%$ annually, and later, in 2009-2017, decreased by $0.1 \%$ annually.

The investments in new electricity generation, along with the low pace of withdrawal of old generators from service, resulted in a substantial surplus of generation capacity. The installed capacity of power plants increased from $212 \mathrm{GWh}$ to $243 \mathrm{GWh}$ in 2009-2018. At the same time, the maximum load rose from $150 \mathrm{GWh}$ to $152 \mathrm{GWh}$, i.e., the regulatory mechanisms of the electric power industry development do not guarantee balanced construction and commissioning of new generation capacities in the context of the current electricity demand.

Therefore, the average annual electricity production per unit of installed capacity grew from $4126 \mathrm{kWh} / \mathrm{kW}$ to 4612 $\mathrm{kWh} / \mathrm{kW}$ in 2000-2008. In 2009, electricity consumption decreased due to the economic crisis. In 2016, each $\mathrm{kW}$ of installed capacity produced only $4086 \mathrm{kWh}$ per year, i.e., the production performance in 2016 was lower than that in 2000 (before the industry reform).

The installed capacity of all types of generation grows (Fig. 4), and the production performance differs for various generation types (Fig. 5). For nuclear generation, it increased from $6037 \mathrm{kWh} / \mathrm{kW}$ in 2000 to $7281 \mathrm{kWh} / \mathrm{kW}$ in 


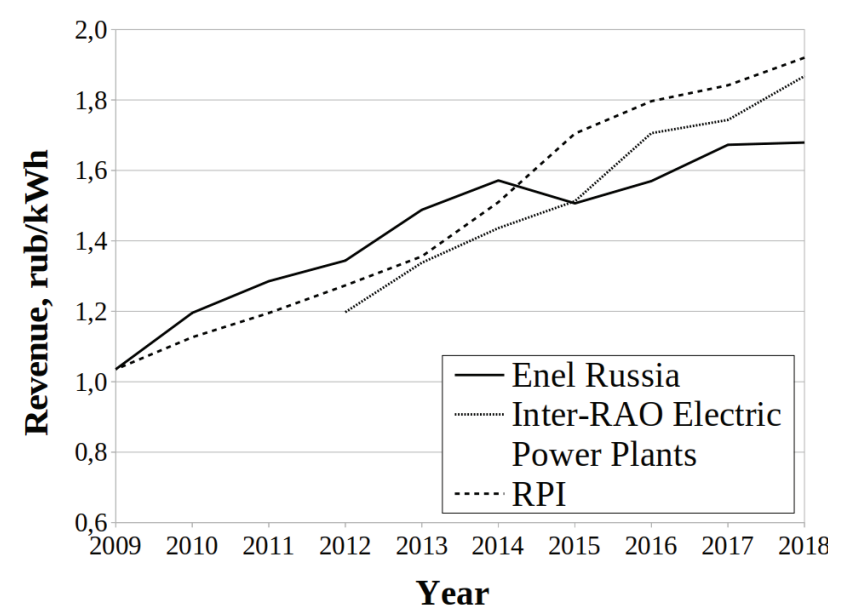

Fig. 7. The revenue from electricity and capacity sales divided by $1 \mathrm{kWh}$ of generated electricity (compared to RPI).

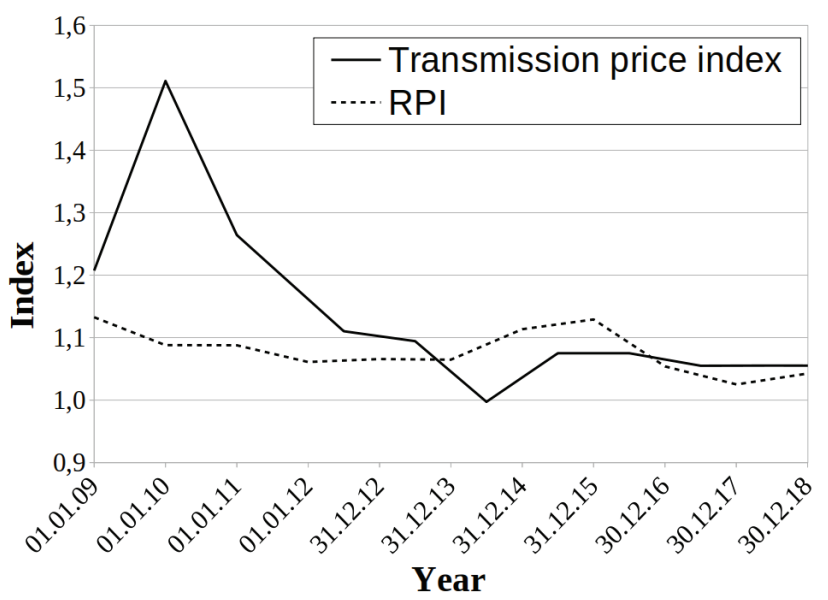

Fig. 9. Electricity transmission prices of the Unified Power System.

2017. At the same time, the same ratio decreased for hydro generation from $3725 \mathrm{kWh} / \mathrm{kW}$ to $3518 \mathrm{kWh} / \mathrm{kW}$. The production performance of thermal power plants increased in 2000-2008. Later, in 2010-2017, it dropped from 4424 $\mathrm{kWh} / \mathrm{kW}$ to $3687 \mathrm{kWh} / \mathrm{kW}$, i.e., it became $16,7 \%$ lower. The power capacity factor of thermal power plants in 2017 was only $42.1 \%$. It reveals discrimination of thermal generation in favor of nuclear one.

Such dynamics of the power capacity factor pose risks for the industry and provoke either growth in electricity prices or a decrease in the producers' profits. Less electricity generated by a power plant means smaller variable costs but the fixed costs remain the same. Thus, some producers need a higher market price to cover the fixed costs if they are not covered by the capacity payments. In this case, the wholesale electricity prices may grow more quickly than the prices of the fuel consumed by the plant.

Fig. 6 shows the prices in the day-ahead market in both price zones.

Prices in price zone I of the day-ahead market grew above the inflation rate in 2010, and later, the growth was equivalent to the RPI change. In 2009-2017, the price in

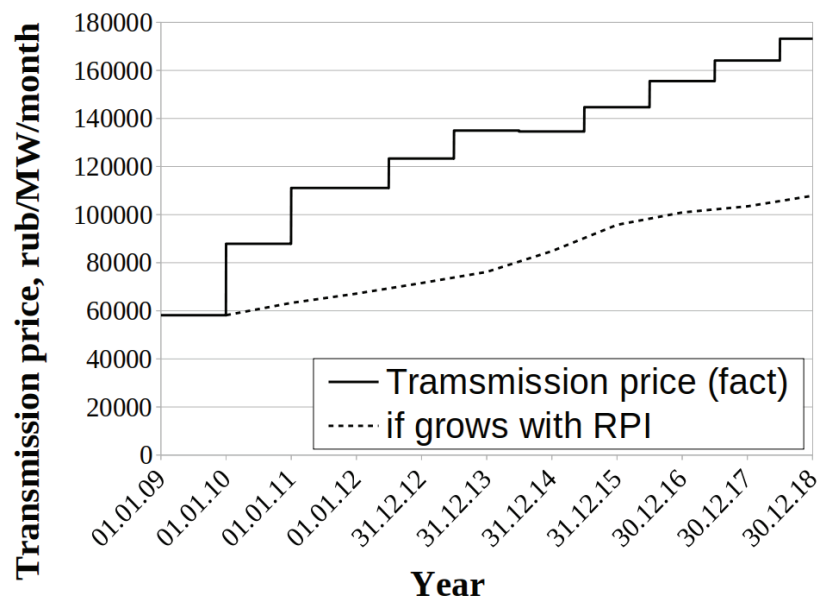

Fig. 8. Electricity transmission prices of the Unified Power System.

price zone I rose by $80 \%$, RPI - by $77.9 \%$, and gas price - by $90 \%$, i.e., the total electricity price growth in the wholesale market was equivalent to the inflation rate and lower than the rise in the dominant fuel price in this price zone.

The dominant fuel of price zone II is coal. Coal price increased in 2009-2017 less than RPI. Within the considered period, the electricity price in the zone increased by $97.8 \%$, coal price - by $57.3 \%$, and RPI - by $77.9 \%$.

To get a complete picture, let us look at the earnings of some generating companies. Fig. 7 indicates a normalized revenue of two wholesale market participants - Enel Russia and Inter-RAO Electric Power Plants (since 2012). The power plants of Enel Russia work in price zone I of the wholesale market. The Figure shows that the normalized revenue of the two companies (including the revenues from electricity and capacity sales) changed similarly to RPI. The normalized revenue of Enel Russia in 2009-2018 increased by $62 \%$, while RPI increased by $85 \%$.

Thus, within the period under review, there is an advanced growth of installed capacity in the sphere of electricity generation. In combination with moderate electricity consumption growth, it results in lower production performance of $1 \mathrm{~kW}$ of installed capacity. The prices in zone I of the day-ahead market changed similarly to gas prices, and the overall increase was equivalent to the retail price index change. The normalized revenue of the two considered producers also increased likewise, or less than RPI. The prices in price zone II increased more quickly than RPI and coal prices, but the difference had become smaller by 2017 .

\section{ELECTRICITY TRANSMISSION}

The major participants in electricity transmission are the Federal Grid Company (FGC) that operates the main transmission system and distribution companies. The FGC prices are shown in Figs. 8, 9.

The diagrams indicate that the grid transmission prices grew rapidly in 2010-2011, and later, they changed similarly to inflation. Nevertheless, due to the fast initial growth, 


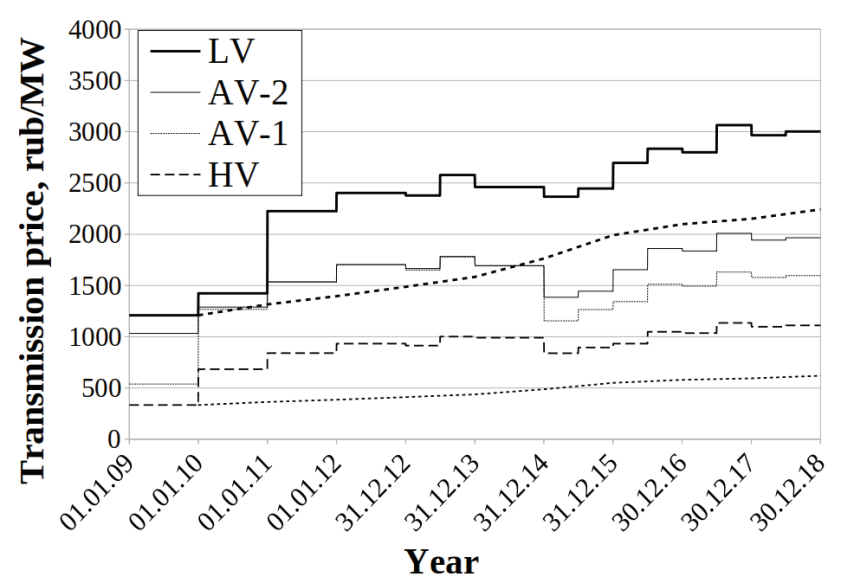

a)

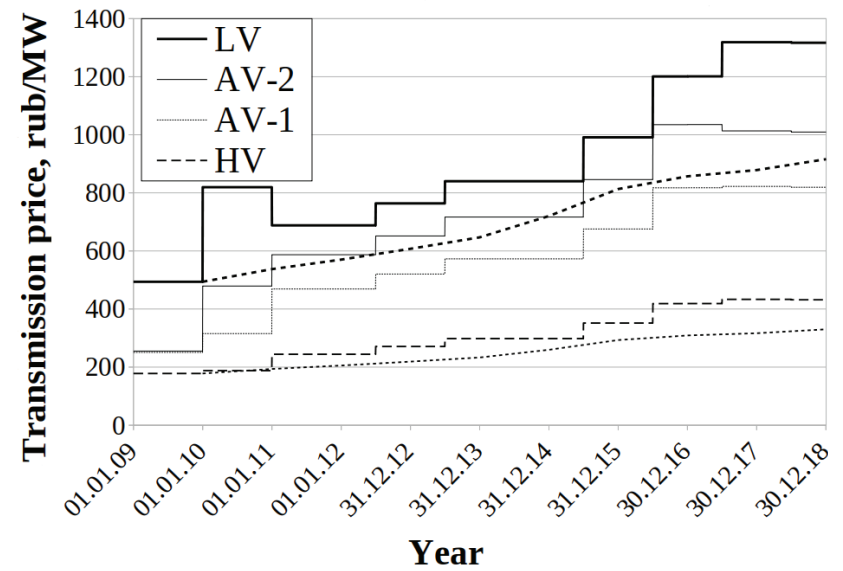

b)

Fig. 10. One-part tariffs of MOESK (a) and IESK (b) for electricity distribution for different voltage levels.

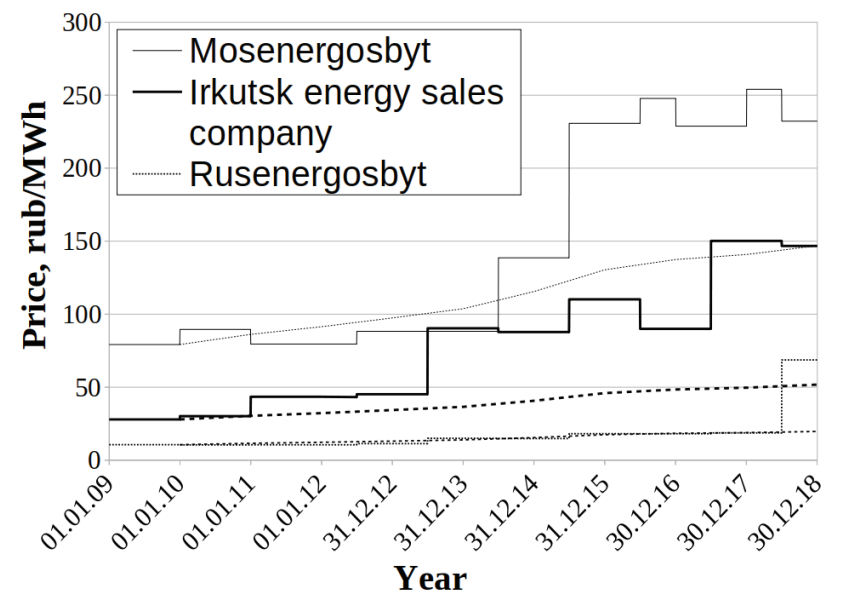

Fig. 11. The household tariffs of Mosenergosbyt, Irkutsk Energy Sales company, and Rusenergosbyt in 2009-2018.

the overall increase was $198 \%$ within the period under consideration. RPI, at the same time, increased by $85 \%$.

To present the situation in distribution networks, let us consider two distribution companies (Rosseti Moscow Region (MOESK) and Irkutsk Network Company (IESK)) and one-part transmission tariffs for four voltage levels: high (HV), first average (AV-1), second average (AV-2) and low voltage (LV). (Fig. 10). The Figures show that the distribution tariffs also increased more quickly than retail prices. For example, the one-part low-voltage tariff of MOESK increased by $148 \%$ within the period under consideration, the second medium-voltage tariff increased by $90 \%$, the first medium-voltage tariff - by $197 \%$, and the high-voltage tariff - by $232 \%$. In the same period, RPI increased by $85 \%$ only. The dynamics of the IESK tariffs were similar.

Thus, the transmission and distribution tariffs rose more quickly than the inflation. Although the growth was distributed non-uniformly and most of the increase occurred in 2010-2011, the overall tariff increase exceeded RPI, in some cases, 1.5-2 times.

\section{SALES}

The sphere of electricity sales is organized as a combination of suppliers of last resort and other suppliers that are not obliged to contract all the coming consumers. The prices of the suppliers of last resort are subject to regulation. The dynamics of the supply tariffs are represented by the suppliers of last resort in the city of Moscow (Mosenergosbyt) and the Irkutsk region (Irkutsk Energy Sales Company, and Rusenergosbyt). The household tariffs are shown in Fig. 11.

The diagram demonstrates that the pace of changes in tariffs under consideration was not steady. However, it is typical of the three suppliers that:

- in the early stage, the tariffs changed likewise the retail price index;

- an overall tariff growth exceeded the retail price index significantly.

- the tariff of Mosenergosbyt in 2018 was 58\% higher than it should have been if it were indexed with RPI. The excessive growth for Irkutsk Energy Sales Company was $184 \%$ and for Rusenergosbyt $-249 \%$.

\section{CONCLUSIONS}

The information and statistical data provided in the paper bring us to the following conclusions concerning the results of the electricity reform and the current regulatory conditions in the Russian electric power industry:

1. The economic situation in 2009-2018 was characterized by stable growth of the total electricity consumption and a lower inflation rate than in the previous decade.

2. The regulatory mechanisms of the electric power industry development do not guarantee balanced construction and commissioning of new generation capacities in the context of the current electricity demand. The provided data on production performance show discrimination of thermal generation in favor of nuclear one and excessive growth of generating capacities.

3. The data on the day-ahead market confirm a relative efficiency of the wholesale market regulatory framework, at least in the first price zone. In the second price zone, the electricity price grew excessively compared with the inflation rate and fuel price. The excessive growth, 
however, is incomparable with the one in electricity transmission and distribution.

4. In electricity transmission and distribution, significant price growth was approved by the regulating authorities. The rise exceeded the retail price index, in some cases, by $200 \%$ and more.

5. In electricity sales, the uneven price growth exceeding inflation was also approved by the regulators. The sales prices do not influence the end consumer costs as much as the transmission prices. Their dynamics, however, require the attention of researchers.

The significant difference between price dynamics in various sub-industries also proves that generation, transmission, distribution, and sales should be considered separately when discussing electricity reform and regulation. Otherwise, the conclusions must be questioned.

\section{ACKNOWLEDGEMENT}

The research was carried out under State Assignment 17.4.4 (reg. number AAAA-A17-117030310449-7) of the Fundamental Research of Siberian Branch of the Russian Academy of Sciences and partly supported by the Russian Foundation for Basic Research, grant 19-010-00183.

\section{REFERENCES}

[1] L.S. Belyaev, Problems of the electricity market. Novosibirsk, Russia: Nauka, 2009, 296 p. (in Russian)

[2] G.P. Kutovoj, "Need for a new paradigm (or architectonics) of economic relations in the electric power industry," Energetik, vol. 2, pp. 8-13, Feb. 2016. (in Russian)

[3] D.G Kolesnikov, "The question of certain results of privatizing the electric power industry of Russia," Science Vector of Togliatti State University. Series: Economics and Management, vol.1 (32), pp. 25-30, Jan. 2018. DOI: 10.18323/2221-5689-2018-1-25-30. (in Russian)

[4] A.B. Chubais, "Russian electric power industry reform: 10 years later," Voprosy Ekonomiki, vol. 8, pp. 39-56, Aug. 2018, DOI: 10.32609/0042-87362018-8-39-56. (in Russian)

[5] I.S. Kozhukhovski, "The key results of the electric power industry reform," Regionalnaja energetika $i$ energosberezhenije, vol. 4, pp. 8-15, Apr. 2018. (in Russian)

[6] A.N. Melnik, I.E. Naumova, R. Kurt, O.N. Mustafina, A.R. Sadriev, "Liberalization of the electricity market in Russia: achievements and problems," Economic Revival of Russia, vol. 3(37), pp. 133-143, Mar. 2013. (in Russian)

[7] V.V. Rashevski. (2018, Feb 6). On the modernization of the thermal power. Presented at Round table "Prospective of electric power industry development: long-term trends." Available at: http://media.rspp.ru/ document/1/4/0/40dd44874502cd043b6f60566821d 25c.pdf. (accessed: 15.01.2021). (in Russian)

[8] V.A. Stennikov, S.I. Palamarchuk, B.O. Golovshikov, "Dimensions of improving the efficiency of the electric power industry," Energosovet, vol. 1(51), pp. 31-37, Jan. 2018. (in Russian)

[9] S.I. Palamarchuk, "Improvement in Russian electricity and capacity markets," in Improvement in the efficiency of energy production and utilization in Siberia, Irkutsk, Russia, 2019, pp. 265-271. (in Russian)

[10] S.I. Palamarchuk, "Efficiency of the electricity markets in Russia," Journal of Engineering Science and Technology, vol. 14, no. 6. pp. 3664-3678. Dec. 2019.

[11] V.O. Golovshchikov, "Problems of electric power industry reform in Russia and their impact on market relations," Energorynok, vol. 5, pp. 30-35, May 2016. (in Russian)

[12] E.V. Lyubimova, "Electric power industry: economic nuances of Russian trends," ECO, vol. 9, pp. 8-22, Sep. 2019. (in Russian)

[13] V.V. Semikashev, "Heat supply in Russia: current state and problems of investment development," $E C O$, vol. 9, pp. 23-47, Sep. 2019. (in Russian)

[14] M. Lamoureux, "Causality-based policy learning frameworks derived from Russian power sector liberalization," Energy Systems Research, vol. 3, no. 1, pp. 5-20, Jul. 2020. DOI: 10.38028/esr.2020.01.0001.

[15] N. Aizenberg, S. Dzuba, "Market power evidence from electricity market of the Russian Federation," $E C O$, vol. 10, pp. 102-126, Oct. 2020, DOI: 10.30680/ ECO0131-7652-2020-10-102-126. (in Russian)

[16] M.Yu. Vasilyev, "The components of electricity price," in Models of markets with imperfect competition: application to the electric power industry, Irkutsk, Russia: Melentiev Energy Systems Institute, 2015, pp. 72-82. (in Russian)

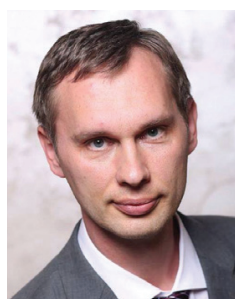

M. Yu. Vasilyev was born in Irkutsk, Russia. He graduated from Irkutsk State Technical University in 1997, received a Ph.D. degree in 2002. Currently, he is a researcher at Melentiev Energy Systems Institute SB RAS, Irkutsk, Russia. His research interests include regulation and industrial organization of the electric power industry. 